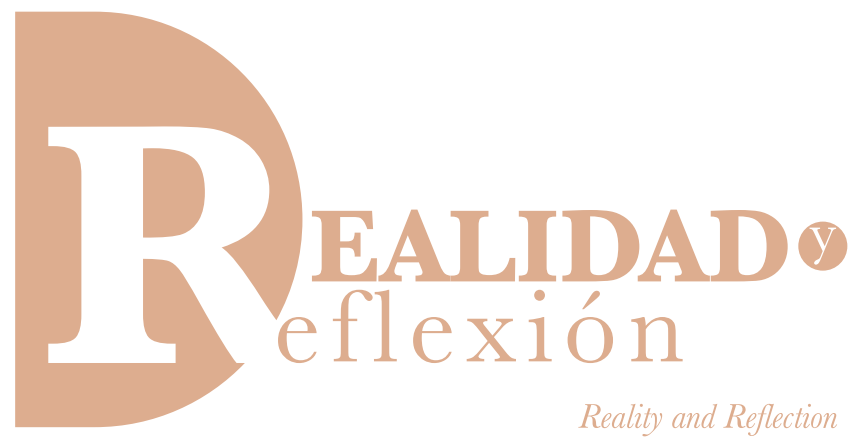

ISSN 1992-6510

e-ISSN 2520-9299

Año 17, N 46, San Salvador, El Salvador, Centroamérica. Revista Semestral Julio-Diciembre 2017

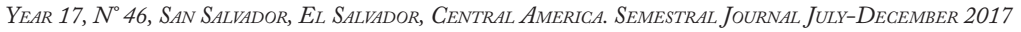

\title{
Los troles políticos
}

\section{Political trolls}

\author{
Ana Evangelina Aguilar ${ }^{1}$ \\ Licenciada en Periodismo y Comunicaciones \\ Universidad Centroamericana José Simeón Cañas, UCA. \\ Máster en Asesoría de Imagen y Consultoría Política \\ Universidad Pontificia de Salamanca, España. \\ Investigadora para el área de comunicación ICTI-UFG \\ aeaguilar@ufg.edu.sv \\ Recibido: 12 de octubre de 2017 \\ Aprobado: 27 de noviembre de 2017 \\ pág. $67-75$ \\ DOI: http://dx.doi.org/10.5377/ryr.v0i46.5508
}

\section{RESUMEN}

En internet se utiliza el término trol (troll) aplicado a alguien que tiene como finalidad desestabilizar una discusión sobre un tema específico. Estos personajes a través de provocaciones buscan desviar la atención de una temática hacia ideas banales o temas superficiales. Otros troles tienen como misión formular, desde sus perfiles, contenido difamatorio de personas o situaciones particulares. Este artículo pretende delinear, con un abordaje muy general, a los troles digitales desde un punto de vista de la comunicación política y el papel que desarrollan en las comunidades virtuales.

Palabras clave: Comunicación digital, troles, comunicación política, campaña sucia, ciberejércitos.

\section{ABSTRACT}

In the web, the term Troll is used to refer to someone whose intention is to disrupt a discussion of a specific topic. These characters, using provocations, try to deviate the attention from a topic to superficial ideas. There are other kind of trolls, whose objective, is to defame other people or specific situations. This article will delineate in a broad approach, digital trolls from the point of view of the political communication, and the role they play in virtual communities.

Keywords: digital communications, trolls, political communication, negative campaign, cyber attacks.

1 (c) Ana Evangelina Aguilar 


\section{Introducción}

Los políticos de todas las ideologías saben bien que manejando el lenguaje, construyendo discursos, elaborando mensajes pueden construir realidades. En las últimas décadas han aprendido también que para dicha construcción, Internet es una de las plataformas más importantes ya que a través de esta herramienta pueden propagar sus mensajes de una manera muy simplificada. Basta con edificar una comunidad interconectada, fuerte y muchas veces que tintes radicales. De tal manera que lo que nazca como un tuit o post sea capaz de desencadenar una serie viral de comentarios, memes y debates en todos los ámbitos de la sociedad, que tiene el poder de manipular a la opinión pública e incluso influir en los resultados electorales.

Si bien en países latinoamericanos algunos analistas hablan de minorías activas en la red, no se puede ignorar la creciente influencia que las redes sociales y los periódicos digitales tienen, sobre todo en países como El Salvador. Este paulatino dominio ha provocado que los medios tradicionales se conviertan rápidamente en medios multimedia y que los principales temas ya no solo se debatan dentro de los parlamentos o espacios políticos sino que también sean importantes las discusiones en foros digitales, perfiles de Facebook o cuentas de Twitter.

La red, a través de sus comunidades digitales, tiene la potencialidad de transformar las posiciones políticas en historias, puede agrupar o disgregar a la opinión pública a través de conceptos y mensajes; pero qué sucede cuando dicha red está manipulada por medio de troles que emiten información, que puede ser cierta o no; que desarrollan campañas sucias que viralizan contenidos entre miles de seguidores o que crean ruido distorsionando los mensajes que pueden ser positivos dentro del entorno. Dichos troles pueden convertirse incluso en portavoces que determinan agenda de los temas que se discuten en las redes sociales.

Los troles le apuestan a la red y a la manera en la que funciona, en la comunicación directa, la interconexión y la fácil multiplicación de los contenidos. La simplificación del lenguaje y los mensajes, el atractivo de las imágenes, el humor de los videos cortos, etc. A lo largo de este artículo que analizará a los troles haciendo un breve repaso conceptual, así como algunas de los ámbitos en los que se desarrollan. También se delineará el papel que éstos desarrollan dentro del ámbito político y las posibles consecuencias.

\section{Los troles}

Un trol es un individuo que publica falsas acusaciones o comentarios calumniosos en las redes sociales para promover una causa o acosar a alguien. $\mathrm{El}$ anonimato permite a la gente decir cosas que no diría en persona, con el fin de generar fuertes reacciones en muchas de ellas de tipo negativo (Ziff Davis Publishing Holdings Inc, 2009). También un trol, troles en plural, puede implantar mensajes con diferente tipo de contenido como groserías, mentiras embarazosas o difíciles de detectar, con la intención de confundir y ocasionar sentimientos encontrados en los demás.

Por otro lado, en la Universidad de Lancaster, en Reino Unido, específicamente en el departamento de lingüística cuando analizaron 
este fenómeno definieron a un trol como "alguien que aparenta un deseo sincero de formar parte de una comunidad, pero cuya intención real es irrumpir en la conversación o conseguir exacerbar un conflicto, con el único propósito de entretenerse" (Griffiths, 2014). El término trol es conceptualizado por algunos usuarios de Internet al referirse a una criatura mitológica que se esconde bajo puentes, esperando una oportunidad para saltar (Herring, Job-Sluder, Scheckler, \& Barab, 2002).

También está la contraparte que cree que el concepto original de los troles es mucho más amigable ya que nació con el fin de diversión y no como provocación; y es la que se refieren al término acuñado a principios de los años 90 en alt.folklore.urban (grupo de noticias populares de Usenet, precursor de los foros de discusión actuales). Con el fin de descubrir a los recién llegados (newbies), y además distanciarse de ellos, los usuarios experimentados publicaban temas que ya se habían discutido plenamente en ocasiones anteriores, como una especie de truco en donde solo los nuevos comentaban.

Dicho proceso, en el que solo el jet set participaba, fue denominado como "trolling for newbies". Así entonces tiene más sentido la explicación del concepto de trol —aparte de ser la criatura mitológica, como la técnica de pesca, que consiste en arrastrar varios aparejos desde una embarcación y atraer a los peces con cebos. Un tema colocado en la web o en una red social para que caigan otros usuarios.

Esta corriente considera que un trol es una persona graciosa de Internet que busca bromear con los demás dentro de una comunidad virtual.
Por lo que trolear es hacer que alguien tome en serio una broma; por ejemplo, un post en Facebook que tenga un título que sugiera una cosa muy diferente a lo que en verdad esconde, en muchas ocasiones el contenido tiene un fuerte componente de humor, por lo que la acción se convierte en una broma.

Entonces si en los noventa un trol tenía como misión el humor, compartir contenido gracioso y hacer bromas ¿cuándo fue que se deformó a ser un individuo que irrumpe conversaciones, causa reacciones negativas e incluso difama?

Una década después esta acción que realizan los troles, a la cual se le denomina trolear -en Inglés trolling-, se cruzó con otra actividad muy similar: el flame (traducido algunas veces como desahogo) consiste en un mensaje deliberadamente hostil o insultante enviado sin ningún propósito constructivo, sino por el contrario dicho mensaje se caracteriza por ser provocativo y generar respuestas acaloradas (Dominique, 1997). Ya que los dos (trol y flamer) desempeñan el papel de poner cebos o mensajes en la red es que hoy en día hay una dualidad en la idea del trol ya que está el trol que es gracioso, bromista, y el trol flamer, hiriente, que se cuela en las conversaciones para sacar a los usuarios de sus cabales.

Así los graciosos tienen como función engañar y hacer bromas, son dinámicos, entretenidos y muy creativos en sus participaciones. A ellos se les puede adjudicar ser precursores de los memes (ragefaces, feel like a..., forever alone, etc.). Los trol flamer son diferentes en su función, son obscuros y se aprovechan del anonimato para ser crueles, la idea es provocar y desestabilizar. Este tipo de 
troles son una especie de matones (bully en inglés, término que deriva en bullying o acoso escolar). Estos troles tienen una conducta agresiva hacia otro usuario a través de un comportamiento que constantemente se repite con el fin de producir daño de manera premeditada, dicho comportamiento puede incluso resultar en palabras agresivas y hasta en amenazas.

Existe de hecho una descripción de estos troles que los relaciona con una especie de triada obscura de la personalidad y les denomina como narcisistas, maquiavélicos y psicópatas (Shachaf \& Hara, 2010):

Narcisismo: sentimientos de grandeza y falta de empatía.

Maquiavelismo: tendencia a manipular y explotar a los demás.

Psicopatía: comportamientos antisociales, impulsivos y sin remordimientos.

Estos tres aspectos pueden ser los que definan perfectamente a los troles flamer o hirientes como personas que desarrollan comportamientos impulsivos y antisociales; pero que además en muchos de los casos disfrutan haciéndolo.

Otro estudio desarrollado por la University of British Columbia en el que se analizaron los rasgos de la personalidad de los troles se les denomina también como sádicos (Buckels, Trapnell, \& Paulhus, 2014). Los científicos examinaron los atributos sádicos que manifestaban algunas de las personas que decían comportarse a veces como troles en la red. Aunque dichos estudios son iniciales, arroja interesantes datos para tratar de comprender la conducta de los usuarios.

\section{El centro de troles}

Si bien un trol puede ser un individuo específico, real, que puede ser gracioso o flamer, también existen aquellos perfiles que son creados en masa, es decir usuarios apócrifos o ficticios de los cuales se valen los troles (generalmente en Facebook o Twitter) con el fin de instalar o manipular conversaciones en las comunidades digitales. Tienen como objetivo burlarse, criticar, hacer comentarios soeces sobre usuarios reales o acciones concretas. Así, a través de diferentes cuentas falsas generan una especie de universos o ruido comunicacional entre la opinión pública.

Estos troles generalmente están concentrados en lo que hoy se denomina como un centro de troles (troll center en inglés), es decir un grupo de usuarios organizados que tienen como finalidad instalar conversaciones o temas dentro de las comunidades digitales. Inyectar información dentro de los procesos comunicacionales en las redes sociales. Por tanto, para que un centro como estos funcione deben manejar mucha información verídica, que no necesariamente debe ser de conocimiento público, conseguir y cruzar información; pero también deben ser individuos creativos en la generación de contenidos e incluso faltar a la ética con temas en los que pueda construirse información falsa que colinde con la difamación.

En los centros de troles se monitorean las redes sociales, el entorno de la red, con el fin de conocer las temáticas o mensajes que pueden afectar a los clientes que los contratan, por ejemplo a los políticos, quienes son los que suelen crear o contratar este tipo de centros de troles; pero no solo los políticos los utilizan, también hay empresas 
que usan estas estrategias digitales para atacar a la competencia o productos, campañas, específicos.

El periódico La Nación de Argentina en una publicación referente a este tema entrevistó al especialista Federico Landera, de la consultora Parodoxia, este indicó que en muchos casos las consultoras crean distintos usuarios y les dan una suerte de vida paralela. Además agregó que los costos de este tipo de servicio varían, las consultoras cobran aproximadamente unos dos mil quinientos dólares mensuales y que incluso para usar las aplicaciones de difusión masiva sin intermediación de una consultora hay que pagar. Para gestionar una sola cuenta, el servicio suele ser gratuito. Para controlar varias, se abona. Los costos varían entre los 50 y los 100 dólares por mes para manejar diez, quince o veinte cuentas, según el programa.

Ahora bien, los centros de troles pueden ser creados o contratados para diversos fines; pero es el objetivo político el que capta la atención en muchos de los casos, ya que estos directamente buscan manipular la opinión pública.

En El Salvador, el pasado agosto, el actual candidato a la Alcaldía de San Salvador por el partido ARENA, Ernesto Muyshondt, aseguró que el actual Alcalde, Nayib Bukele, invierte aproximadamente $\$ 35,000$ mensuales en salarios para mantener un centro de troles con el fin de que hablen bien en las redes sociales de la gestión del edil: "Tengo las actas del Instituto Municipal de la Juventud y es una lástima que se gasten $\$ 35,000$ mensuales en pagar un troll center, eso no se vale" (www.elsalvadorgram. com, 2017). Esta no es la única declaración que el candidato ha realizado con respecto al tema, en el año 2015, también habló de los centros de troles sólo que en esta ocasión se refirió a troles pagados por el Gobierno salvadoreño: “...desde el atardecer del martes pasado hay gente muy nerviosa que teme que la captura del también exempleado de Casa Presidencial se convierta en un ficha de dominó que implique la caída de uno, dos, tres o más peces gordos que por oficio tiene la difamación en el ciberespacio" (www. diario1.com, 2015).

En los últimos años, en los pasillos políticos no sólo se hacen referencias al actual Alcalde de San Salvador como usuarios y empresarios de centros de troles sino también se ha mencionado al expresidente salvadoreño, Mauricio Funes: "Dicen que el alcalde de San Salvador (Nayib Bukele) está detrás de muchos troll centers, agregó (Ernesto Muyshondt) y que incluso el expresidente Mauricio Funes se podría estar dedicando a esas prácticas" (www. diario1.com, 2015).

\section{Troles electorales}

Los troles o los centros de troles, a través de sus usuarios apócrifos, son contratados para desarrollar estrategias digitales de campaña en las que pueden generar un ambiente negativo o positivo hacia un político. A través de una estrategia digital se puede posicionar un candidato, sus mensajes, el discurso, sus propuestas de campaña, etc.; pero no solo es posicionamiento, también pueden desarrollarse diversos elementos de la campaña sucia. Los políticos apelan a usuarios que ayudan a la popularidad de su imagen, que engañen a los usuarios de ciertas redes de temas que tienen verdadera relevancia o que perjudiquen la imagen de los rivales. 
Para Katheryn Hernández (2015) las mentiras y engaños que los troles diseminan en las redes sociales son útiles solamente en la medida en que no se pueden desmentir, ya que la web es un mar donde se crea, se difunde y se olvida la información en cuestión de horas. Los troles suelen surgir más en las épocas electorales, desean dañar imágenes específicas, quieren generar confusiones y por ende, restarle votos al candidato. Por lo general, dichos usuarios crean un Trending Topic (tendencia) de un tema particular.

Especialistas en marketing político y analistas de este tema concuerdan al decir que generalmente los candidatos o los partidos políticos que más dinero tienen para invertir en estas estrategias, son los que tienen la capacidad de contratar consultoras o empresas dedicadas al marketing digital que se especializan en la difusión de contenidos a través de Internet.

Otro aspecto a considerar es que los partidos políticos también hacen uso de sus militantes quienes usan las redes sociales con el fin de difundir alguna noticia, información, etc. y que muchas veces terminan cumpliendo el papel de troles. Estos no necesariamente desarrollan este papel de manera voluntaria más bien caen en una dinámica en la que muchas veces está siendo manipulada por algún perfil apócrifo.

Para Miguel Jaramillo Luján, consultor colombiano en marketing político, existen tres tipos de troles: los haters, los duplicadores y los reportadores (Luján, 2016):

Haters: Son los más comunes. Se trata de provocadores quienes siempre están buscando llamar la atención de los más incautos con groserías, provocaciones $\mathrm{y}$ muchas veces conduciendo a contenidos con virus o argumentos de dudosa credibilidad.

Duplicadores: Generan cuentas ficticias para insultar, confundir, generar desprestigio o afectar la imagen y-o reputación de candidatos o dirigentes políticos.

Reportadores: Son de bajo perfil y buscan -sobretodo- que las cuentas originales exitosas y masivamente apoyadas, sean sacadas del aire, al provocarlas con insultos y a partir de una respuesta real o ficticia, reportarla al operador de la red social como no adecuada a las normas de una red social.

Cualquiera de estos tres perfiles de troles puede ser fácilmente ubicado en la red, y son de mayor ubicación dentro de las redes sociales de los políticos. Basta con entrar a perfiles de candidatos o de funcionarios públicos para conocer su modo de actuar en los temas de coyuntura, reproducen generalmente el mismo discurso.

\section{Los ciberejércitos de troles gubernamentales}

Un informe de la Universidad de Oxford señala que no son las agencias de publicidad, ni empresas con fines económicos las crean los centros de troles, son más bien los gobiernos los que hacen que la práctica trol sea parte de la estrategia de comunicación gubernamental. Los especialistas del Oxford Internet Institute definieron los ciberejércitos como "equipos gubernamentales, militares o partidarios que se dedican a manipular la opinión pública en las redes sociales”. Muchos países no tienen las propias, "pero participan en pactos mutilaterales de defensa mutua con 
programas para ello". En el informe Troops, Trolls and Troublemakers: A Global Inventory of Organized Social Media Manipulation Samantha Bradshaw y Philip Howard (2017) estudiaron 28 países (entre ellos Argentina, Brasil, México, Venezuela, Ecuador, Estados Unidos, Reino Unido, Alemania, Israel, China, India, Rusia y Corea del Norte) y concluyeron que:

1. "Los ciberejércitos son un fenómeno generalizado y global".

2. "Todos los regímenes autoritarios hacen campañas en redes sociales que apuntan a su propia población, mientras que solo unos pocos apuntan a públicos extranjeros”.

3. "Casi todas las democracias tienen campañas en redes sociales que apuntan a públicos extranjeros, mientras que las campañas de los partidos políticos apuntan a los votantes locales”.
El anonimato que se puede llegar a alcanzar a través de algunos perfiles falsos dentro de la red sumado a la importancia que tienen las redes sociales para los ciudadanos se combina en muchas ocasiones de una manera no muy positiva. En primer lugar, porque hoy por hoy muchos de los jóvenes están desarrollando y ampliando sus identidades políticas en muchos casos por medio de la red, también es el medio ideal para ellos de informarse sobre lo que está sucediendo en su entorno; en segundo lugar, algunas plataformas como Facebook y Twitter también se han convertido en herramientas de control social, según Bradshaw y Howard (2017).

Por ejemplo, en dicho informe, los investigadores designaron en un mapa el modo en que los troles oficiales u oficiosos - los hay empleados directos de los gobiernos, los hay contratistas independientes - trabajan con el fin de influir sobre las corrientes de información.

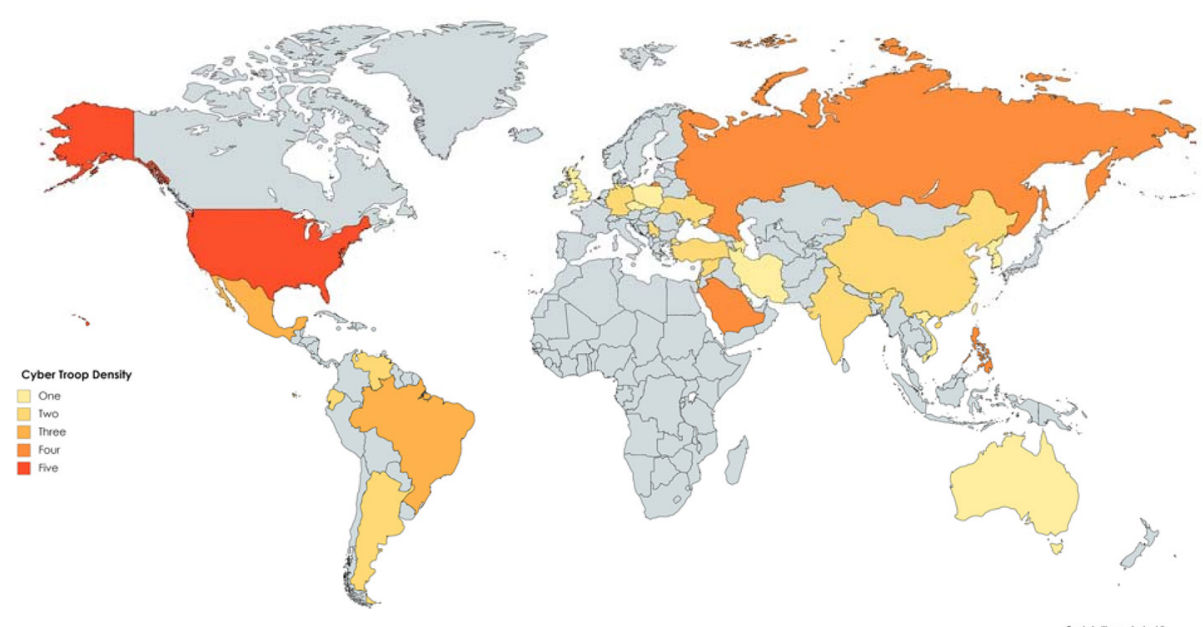

Ilustración n. ${ }^{\circ}$ 1. Densidad organizativa de los ciberejércitos. Fuente: Troops, Trolls and Troublemakers: A Global Inventory of Organized Social Media Manipulation 
Los países resaltados con rojo son los que tienen mayor actividad y los que tienen color amarillo los que de menor actividad de los 28 estudiados.

Los investigadores manifiestan que en dicha figura los países con muchas clases de organizaciones (gobiernos, partidos políticos, grupos de la sociedad civil, ciudadanos organizados o contratistas independientes) aparecen en el matiz más oscuro del rojo. $\mathrm{Si}$ bien los fondos suelen ser públicos en los regímenes autoritarios y partidarios en las democracias, "en muchos países los ciberejércitos tienen una multiplicidad de afiliaciones, financistas o clientes" (Bradshaw \& Howard, 2017).

La manera en la que actúan estos ciberejércitos es a través de la manipulación organizada. "Algunos ciberejércitos se concentran en mensajes positivos que refuerzan o apoyan la posición o la ideología oficial", según lo manifiestan los investigadores Bradshaw y Howard; pero por otro lado, "las interacciones negativas implican abuso verbal, acoso o provocación de individuos con posiciones críticas del gobierno".

Otra de las maneras más comunes que tienen de actuar los ciberejércitos es atacando de manera metódica y continua a un individuo o un grupo influyente en las redes sociales. Así la forma más conocida es el acoso, que por lo general implica abuso verbal, discriminación y/o trolling contra los valores, las creencias o la identidad de un usuario o un grupo.

Según la investigación que dio pie al informe las cuentas falsas complementan a las cuentas de los gobiernos y la creación de contenidos (entradas de blogs, videos de YouTube, noticias falsas, fotos o memes) es una de las formas más comunes de operación psicológica. A veces los ciberejércitos son equipos que integran las organizaciones oficiales, como el Departamento de Educación y Propaganda de Vietnam, el Ministerio de Comunicaciones de Venezuela o la Brigada 77 de los militares británicos. Y en China, la administración pública detrás de sus actividades es increíblemente vasta, con estructuras regionales. En Argentina y en Ecuador han sido vinculadas con la oficina presidencial (Bradshaw \& Howard, 2017).

\section{Conclusión}

Hay perfiles de usuarios en la web que cumplen perfectamente con un perfil de trol, ya sea bromista o flamer, que tienen como objetivo difundir mensajes equivocados o manipular la información sobre un tema o suceso de importancia para la opinión pública; pero también existen centros de troles configurados para manosear las ideas y/o mensajes hacia los ciudadanos ya sea desde instituciones como partidos políticos o los mismos gobiernos. Comprender que el papel de estos troles es desestabilizar y desviar la atención sobre los temas importantes es responsabilidad de los usuarios, así como no responder a ningún comentario ya que la mejor manera de combatir a un trol es ignorándolo. Los políticos han encontrado una manera muy efectiva de lidiar en las redes sociales con los troles y es bloqueándolos; pero cuidado con aislar de sus redes a aquellos que no son troles sino más bien ciudadanos que están ejerciendo su derecho a la libertad de expresión al cuestionar o emitir su punto de vista, ya que en lugar de deshacerse del trol puede provocarse una crisis de imagen en redes sociales que no le conviene. 


\section{Bibliografía}

Bradshaw, S., \& Howard, P. (2017). Troops, Trolls and Troublemakers. Oxford: University of Oxford.

Buckels, E., Trapnell, P., \& Paulhus, D. (2014). Trolls just want to have fun. ScienceDirect, 97-102. Recuperado de: http://www. sciencedirect.com/science/article/pii/ S0191886914000324

Dicen que alcalde de San Salvador está detrás de muchos troll center. (12 de noviembre de 2015). Diario 1.com. Recuperado de: http:// diario1.com/politica/2015/11/dicen-quealcalde-de-san-salvador-esta-detras-demuchos-troll-center/

Dominique, N.(1997). La conquista del ciberespacio. Santiago de Chile: Editorial Andrés Bello.

Griffiths, M. (2014). Adolescent trolling in online environments: A brief overview. Education and Health, 32(3), 85-87. Obtenido de http://sheu.org.uk/sheux/eh323mg.pdf

Hernández, K. (30 de noviembre de 2015). Los trolls en la política y la propaganda negra. Clases de periodismo. Recuperado de: http:// www.clasesdeperiodismo.com/2015/11/30/ los-trolls-en-la-politica-y-la-propagandanegra/
Herring, S., Job-Sluder, K., Scheckler, R., \& Barab, S. (2002). Searching for safety online: Managing "Trolling" in a feminist forum. The Information Society, 371-384.

Iraheta, S. (15 de agosto de 2017). Muyshondt asegura tener pruebas de que Bukele invierte $\$ 35,000$ al mes en su Troll Center. El Salvadorgram.com. Recuperado de: https:// elsalvadorgram.com/2017/08/ernestomuyshondt-asegura-pruebas-bukeleinvierte-35000-al-mes-troll-center/

Luján, M. J. (18 de marzo de 2016). Qué es un troll en la política. El colombiano. Recuperado de: http://www.elcolombiano.com/blogs/ plazapublica/\%C2\%BFque-es-un-troll-enla-politica-2-0/286

Shachaf , P., \& Hara, N. (2010). Beyond vandalism: Wikipedia trolls. Journal of Information Science, 36, 357 - 370.

Straight Dope (2009). What is a troll? Recuperado de: http://www.straightdope. $\mathrm{com} /$ columns/read/1764/what-is-a-troll 